\title{
Risperidone in Children and Adolescents with Conduct Disorder: A Single-Center, Open-Label Study
}

Eyüp Sabri Ercan, MD, ${ }^{1}$ Ayşe Kutlu, MD, ${ }^{1}$ Sibel Çıkoğlu, MD, ${ }^{1}$ Baybars Veznedaroğlu, MD, ${ }^{2}$ Serpil Erermiş, MD, ${ }^{1}$ and Azmi Varan, PhD $^{2}$

Departments of ${ }^{1}$ Child and Adolescent Psychiatry and ${ }^{2}$ Psychiatry, Ege University, School of Medicine, Bornova, Izmir, Turkey

\begin{abstract}
Background: Risperidone is one of the most commonly used atypical antipsychotic drugs in the treatment of children and adolescents. However, the data about its use in children and adolescents with conduct disorder (CD) are limited.

Objective: The aim of this study was to investigate the effectiveness and tolerability of risperidone in controlling major symptoms of CD in children and adolescents diagnosed with attention deficit hyperactivity disorder (ADHD), oppositional defiant disorder (ODD), and severe CD.

Methods: Children and adolescents were eligible for this single-center, openlabel study if they met the Diagnostic and Statistical Manual of Mental Disorders, Fourth Edition (DSM-IV) diagnostic criteria for ADHD and ODD and also were diagnosed with severe CD. The patients were treated with risperidone in an open-label fashion for 8 weeks, starting at a daily dosage of $0.25 \mathrm{mg}$ or $0.5 \mathrm{mg}$ (depending on their body weight) in 2 divided doses.
\end{abstract}

Results: The study population comprised 21 children and adolescents (17 boys, 4 girls) with a mean (SD) age of 10.8 (3.6) years. The mean (SD) dosage of risperidone at the end of 8 weeks of treatment was $1.27(0.42) \mathrm{mg} / \mathrm{d}$ (range, $0.75-2.0 \mathrm{mg} / \mathrm{d}$ ). On the basis of the global improvement subscale of the Clinical Global Impression scale, 16 of 20 patients (80\%) were classified as responders. Significant improvements were observed after risperidone treatment in the inattention, hyperactivity/impulsivity, ODD, and CD subscales of the Turgay $D S M-I V$-Based Child and Adolescent Behavior Disorders Screening and Rating Scale (parent and teacher forms). No severe adverse events were reported.

Conclusions: The results of this study are consistent with previous findings and suggest that risperidone may be an effective and well-tolerated atypical antipsychotic drug for the treatment of children and adolescents with CD. However, further studies, particularly placebo-controlled and double-blinded, are 
needed to better define the clinical use of risperidone in children and adolescents with CD. (Curr Ther Res Clin Exp. 2003;64:55-64) Copyright $\odot 2003$ Excerpta Medica, Inc.

Key words: risperidone, conduct disorder, attention deficit hyperactivity disorder, oppositional defiant disorder.

\section{INTRODUCTION}

Conduct disorder (CD) is one of the most common psychiatric disorders in childhood and adolescence. ${ }^{1}$ Aggressive behavior, lying, stealing, running away from home and school, and fire setting are the most common symptoms of the disorder. These symptoms are often accompanied by hyperactivity, impulsive behavior, explosiveness, cognitive and learning problems, and poor social skills. ${ }^{2}$ Several follow-up studies of children diagnosed with $\mathrm{CD}$ have reported high occurrences of adult antisocial behavior. ${ }^{3}$ The American Psychiatric Association's Diagnostic and Statistical Manual of Mental Disorders, Fourth Edition ${ }^{1}$ (DSM-IV) highlights the especially poor outcome for children whose behavior problems begin early in life. Appropriate early intervention may be another predictive factor of outcome for children with $\mathrm{CD}{ }^{2}$

Antipsychotic drugs are prescribed for as many as half of pediatric psychiatric inpatients and one third of pediatric psychiatric outpatients. Aggression, not psychosis, is the symptom for which antipsychotic drugs are most often prescribed. ${ }^{4}$ Most of the typical antipsychotic drugs tested have shown some effectiveness, but the use of these drugs was associated with a high risk for extrapyramidal symptoms and tardive dyskinesia. ${ }^{5}$ These side effects have limited the use of typical antipsychotic drugs in the treatment of severe behavioral disorders. ${ }^{5}$

Risperidone is one of the most commonly used atypical antipsychotic drugs used in the treatment of children and adolescents. It has properties of potent 5-hydroxytryptamine ${ }_{2}$ and dopamine ${ }_{2}$ receptor antagonists. ${ }^{6}$ The results of previous studies suggest that risperidone therapy may be effective in managing behavioral disturbances of children and adolescents with pervasive developmental disorders, bipolar disorder, and CD. ${ }^{5,7-11}$ Moreover, findings of previous studies ${ }^{12}$ with risperidone also suggest its safety in children and adolescents, particularly when used at low doses.

The aim of this single-center, open-label study was to examine the effectiveness and tolerability of risperidone in controlling major symptoms of CD in children and adolescents diagnosed with attention deficit hyperactivity disorder (ADHD), oppositional defiant disorder (ODD), and severe CD.

\section{PATIENTS AND METHODS}

\section{Patients}

Children and adolescents who were referred to the outpatient unit of the Department of Child and Adolescent Psychiatry, Ege University, İzmir, Turkey, for the 
treatment of severe CD and who met the DSM-IV diagnostic criteria for ADHD and ODD were eligible for the study. Furthermore, patients were included only if they had been found to be refractory to methylphenidate therapy prior to this study.

\section{Instruments}

Three instruments were used to screen patients for this study.

The Child Behavior Checklist for Ages 4-18 (CBCL/4-18) was developed by Achenbach and Edelbrock ${ }^{13}$ and consists of 138 items. The CBCL/4-18 was translated into Turkish, and in a study ${ }^{14}$ done with 4488 Turkish children and adolescents, the Turkish form was shown to be a reliable and valid tool for assessing Turkish children and adolescents.

The second instrument, the Turgay DSM-IV-Based Child and Adolescent Behavior Disorders (T-DSM-IV) Screening and Rating Scale (parent and teacher forms) was developed by Turgay ${ }^{15}$ and adapted by Ercan et al. ${ }^{16}$ The T-DSM$I V$ scale is based on DSM-IV diagnostic criteria for inattention, hyperactivity/ impulsivity, ODD, and CD. The T-DSM-IV scale assesses inattention (9 items), hyperactivity/impulsivity (9 items), ODD (8 items), and CD (15 items). The symptoms are scored by assigning a severity estimate for each symptom on a 4 -point Likert-type scale $(0=$ not at all, $1=$ just a little, $2=$ quite a bit, and $3=$ very much). Subscale scores on the T-DSM-IV are calculated by summing the scores on the items of each subscale.

The Clinical Global Impression (CGI) scale ${ }^{17}$ is a clinician-rated scale that is used to assess severity of illness and global improvement, both of which are rated on a scale of 1 to 7 . Lower scores reflect reduced psychopathology and greater therapeutic effectiveness.

\section{Recruitment and Screening Phase}

Recruitment and screening procedures were designed to collect a carefully diagnosed sample of children and adolescents with severe CD. Children were first interviewed by the senior author (E.S.E.). Those who met $D S M-I V$ criteria for $\mathrm{CD}$ were given a set of assessment tools to be completed by the child's parents and teachers. The returned forms were scored; children who scored $>2$ SD above the Turkish national means on the aggression and delinquency subscales of the CBCL/4-18 ( $>53.4$ [6.0] for the aggression subscale and $>53.8$ [6.3] for the delinquency subscale) were called for a second interview. Another child psychiatrist conducted the second diagnostic interview using DSM-IV criteria. The children who were diagnosed with $\mathrm{CD}$ in the same way by both investigators were included in the study. The parents and the children were informed about the study, and written informed consent was obtained from one of the parents and assent from the children prior to the titration phase.

Patients were included in the study if they met the following inclusion criteria: (1) written informed consent was provided by a parent; (2) age of 6 to 16 years; (3) met the DSM-IV diagnostic criteria for childhood-onset (ie, onset prior to 
10 years of age), severe CD (ie, displaying excessive conduct problems that cause considerable harm to others), as well as ADHD and ODD; (4) CBCL/4-18 aggression and delinquent behavior subscale scores $>2$ SD above the Turkish national means; and (5) at least 4 symptoms of $C D$ on the CD subscale of the T-DSM-IV scale.

Patients were excluded from the study if they (1) had a debilitating medical condition or mental retardation (full-scale intelligence quotient [IQ] $<80$, as measured by the Wechsler Intelligence Scale for Children ${ }^{18}$ ); (2) had abnormal findings on laboratory screening of kidney and liver functions; (3) had any comorbid psychiatric condition other than ADHD and ODD; (4) had a Kovacs Depression Inventory ${ }^{19}$ score $\geq 18$ (indicating major depression); (5) had a contraindication (eg, because of suicidal or homicidal risk) of risperidone monotherapy (except benztropine, which none of the cases in the study required); (6) were female and sexually active (because pregnancy tests were difficult to obtain for cultural reasons); or (7) were receiving behavioral therapy or psychotherapy or had received other psychotropic drugs within 30 days of baseline.

\section{Design and Medication}

The patients were treated with risperidone in an open-label fashion for 8 weeks, starting at a daily dosage of $0.25 \mathrm{mg}$ or $0.5 \mathrm{mg}$ given in 2 divided doses, depending on their body weight ( $\leq 45 \mathrm{~kg}$ and $>45 \mathrm{~kg}$, respectively). The medication was individually regulated, with incremental increases up to $0.5 \mathrm{mg} / \mathrm{d}$ no more than once a week until optimal therapeutic effects were observed. Patients visited the unit once a week for the first 4 weeks, and the final assessment was performed at the end of week 8 . No other psychotropic drugs were administered during the trial.

To assess the effectiveness of the drug treatment, parent and teacher forms of the T-DSM-IV scale and severity of illness and global improvement subscales of the CGI scale were used. Parent and teacher forms of the T-DSM-IV scale were completed at baseline and at the end of the study. CGI severity of illness subscale ratings were completed at baseline and at the end of weeks 4 and 8 , whereas CGI global improvement subscale ratings were completed at the end of weeks 4 and 8 . Responders were the patients who were rated as "very much improved" or "much improved" at the end of the study according to the global improvement subscale of the CGI; patients with other ratings were considered nonresponders.

\section{Monitoring Adverse Events}

All patients underwent a complete review of current health status, which included a careful medical history. Complete blood cell counts, liver function tests, and electrocardiograms were performed at baseline and at the end of the study. The Extrapyramidal Symptom Rating Scale ${ }^{20}$ (ESRS) was used in the assessment of extrapyramidal adverse events at baseline and at the end of weeks 
4 and 8. Patients found to have extrapyramidal symptoms were to be treated with benztropine. Body weight gain and sleep duration also were assessed at baseline and at the end of weeks 4 and 8 .

\section{Statistical Analysis}

Data are reported as mean (SD). Data were analyzed with the Statistical Package for the Social Sciences version 10.0.1 (SPSS Inc., Chicago, Illinois). Pairedsample $t$-test and Pearson product moment correlation were used in the analyses of numeric variables. Alpha levels $\leq 0.05$ were considered significant.

\section{RESULTS}

Twenty-one patients were screened for the study. During screening, the mean (SD) CBCL/4-18 aggression and delinquent behavior subscale scores for the group on aggression and delinquent behavior subscales were 77.28 (8.03) and 73.00 (5.07), respectively. The most common reasons for excluding patients from participation in this study were suspected major depression, inability to receive risperidone monotherapy, and full-scale IQ $<80$.

Twenty-one children and adolescents (17 boys and 4 girls) with a mean (SD) age of 10.8 (3.6) years were enrolled. All 21 patients were classified as having severe CD: 14 patients were aggressive toward others, 4 were involved in stealing, 2 ran away from home, and 1 was referred for fire setting. The mean (SD) full-scale IQ for the group was 103.95 (11.01).

Twenty of the 21 patients completed the 8-week study period. The only patient who withdrew from the study did so at the end of week 4 because his parents believed that he was not benefiting from the drug treatment.

The mean (SD) dosage of risperidone at the end of week 8 was $1.27(0.42) \mathrm{mg} / \mathrm{d}$ (range, $0.75-2.0 \mathrm{mg} / \mathrm{d}$ ).

\section{Efficacy Assessment}

The mean (SD) baseline illness severity rating, based on the CGI severity of illness subscale, was $6.4(0.5)$, with 12 patients (60\%) rated "severely ill" and $8(40 \%)$ rated "very severely ill." At the end of the study, the mean CGI severity of illness subscale was 3.2 (1.2). Significant improvements were found in the severity of illness ratings after 8 weeks of treatment $(P<0.001$; Table).

On the basis of a rating of "much improved" or "very much improved" on the global improvement subscale of the CGI scale, 16 patients (80\%) were classified as responders. The 4 nonresponders (20\%) were rated as "minimally improved" (2 patients), "unchanged" (1), and "minimally worse" $(1)(P<0.005)$.

Mean baseline and end-of-treatment ratings of T-DSM-IV subscales are shown in the table. Significant improvements were observed after risperidone treatment in all subscales (inattention, hyperactivity/impulsivity, ODD, and CD) of the T-DSM-IV scale $(P<0.001$ for all). At the end of week 8, CGI assessments of severity of illness and global improvement were significantly correlated with 
Table. Mean behavioral ratings at baseline and at end of treatment with risperidone.

\begin{tabular}{lccrrr}
\hline Behavioral Rating Score & Baseline* $^{*}$ & $\begin{array}{c}\text { End of } \\
\text { Treatment* }\end{array}$ & $t$ Score & df & $P$ \\
\hline CGI severity of illness $^{\dagger}$ & $6.4(0.5)$ & $3.2(1.2)$ & 10.22 & 19 & $<0.001$ \\
CGl global improvement $^{\ddagger}$ & $2.6(0.8)$ & $2.0(1.0)$ & 3.55 & 19 & $<0.005$ \\
Parent & & & & & \\
DSM-IV inattention & $21.2(3.0)$ & $15.3(3.5)$ & 7.16 & 19 & $<0.001$ \\
DSM-IV H/I & $21.7(2.7)$ & $13.0(3.4)$ & 14.32 & 19 & $<0.001$ \\
$D S M-I V$ ODD & $18.5(2.3)$ & $10.3(3.1)$ & 11.96 & 19 & $<0.001$ \\
DSM-IV CD & $14.0(2.9)$ & $6.4(4.3)$ & 8.65 & 19 & $<0.001$ \\
Teacher & & & & & \\
DSM-IV inattention & $22.2(2.7)$ & $16.1(2.7)$ & 9.46 & 19 & $<0.001$ \\
DSM-IV H/I & $22.4(2.6)$ & $12.8(3.0)$ & 10.02 & 19 & $<0.001$ \\
$D S M-I V$ ODD & $18.2(1.7)$ & $10.5(3.8)$ & 9.20 & 19 & $<0.001$ \\
DSM-IV CD & $12.9(3.0)$ & $5.2(3.7)$ & 8.57 & 19 & $<0.001$ \\
\hline
\end{tabular}

CGI = Clinical Global Impression; DSM-IV = Diagnostic and Statistical Manual of Mental Disorders, Fourth Edition $^{1} ; \mathrm{H} / \mathrm{I}=$ hyperactivity/impulsivity; ODD = oppositional defiant disorder; $\mathrm{CD}=$ conduct disorder. *Values are expressed as mean (SD).

†Scale: 1 = normal, not at all ill; $2=$ borderline ill; $3=$ mildly ill; $4=$ moderately ill; $5=$ markedly ill; $6=$ severely ill; $7=$ among the most extremely ill patients.

¥Scale: 1 = very much improved; 2 = much improved; $3=$ minimally improved; $4=$ no change; $5=$ minimally worse; $6=$ much worse; $7=$ very much worse. Matched-pair $t$ test for CGI global improvement subscale was conducted between the end of week 4 and the end of treatment.

§Scale: 1 = just a little; 2 = quite a bit; 3 = very much. Subscale scores were calculated by summing the scores on the items of each subscale.

both the parent and teacher ratings of $\mathrm{CD}$ on the T-DSM-IV. Correlations between the 2 assessments ranged between $r=0.85$ and 0.93 , indicating a very high level of agreement between the assessments of the clinician, parent, and teacher.

\section{Tolerability Assessment}

No severe adverse events were reported. A common adverse event was body weight gain; patients gained a mean (SD) of $1.6(1.9) \mathrm{kg}$ (range, -1.0 to $6.0 \mathrm{~kg}$ ) during the 8-week study period, representing a mean increase in body weight of almost $4 \%$. Three of the 20 patients (15\%) who completed the study gained $>10 \%$ of their original body weight. Although body weight gain was $\sim 29 \%$ for 1 patient (5\%), we did not consider discontinuing risperidone therapy because of the improvement on the CGI and normal liver function tests.

No clinical evidence of extrapyramidal symptoms was detected with the ESRS. Therefore, no patient required treatment with benztropine. Although all patients exhibited mild sedation in the beginning of the study, this adverse event was transitory. Sleep duration was monitored by parental observation, with a mean sleep increase of 0.9 hour (range, $0-3$ hours). No treatment-related clinically significant changes in complete blood cell count, liver function tests, or electrocardiography were found. In general, risperidone was well tolerated. 


\section{DISCUSSION}

In this open-label trial in children and adolescents with severe CD comorbid with $\mathrm{ADHD}$ and ODD, the use of low-dose risperidone was associated with a decrease in ADHD, ODD, and CD symptoms in a majority of the participants. Using a definition of meaningful response as a score of "much improved" or "very much improved" on the global improvement subscale of the CGI scale, $80 \%$ of patients were rated as responders after 8 weeks of risperidone therapy. Parent and teacher ratings of ODD and CD showed significant improvements in these symptoms. Also, a significant improvement was found in the ratings of severity of illness after 8 weeks of treatment on the CGI severity of illness subscale.

Consistent with our findings, in a double-blind, placebo-controlled study of 20 children and adolescents with $\mathrm{CD}$, Findling et $\mathrm{al}^{5}$ reported that risperidone was superior to placebo in ameliorating aggression on most measures. In that 10 -week trial, 6 of 10 patients (60\%) in the risperidone group completed the study and showed significant improvements on CGI severity of illness and global improvement scores. Turgay et $\mathrm{al}^{8}$ conducted a double-blind, placebo-controlled study of 110 children with severe CD and mental retardation. After a 6-week trial of risperidone versus placebo, they found that risperidone was significantly more effective than placebo in reducing Nisonger Child Behavior Rating Form ${ }^{5}$ conduct problem subscale scores. Reports from studies of risperidone in autistic children and adolescents also have shown that risperidone is a beneficial agent in treating conduct problems. ${ }^{6,12}$ In terms of the scores on the CGI global improvement subscale, the rate of improvement in our study was higher than the rates reported in previous studies ${ }^{5,8}$ of children and adolescents with CD. The higher rate of improvement found in this study could partly be explained by the severity of the CD in our patients. Because only severe cases of CD were included in the study, our patients' scores could improve more.

Significant results obtained on measures of inattention, hyperactivity/ impulsivity, ODD, and CD subscales were also noteworthy. Significant improvement in the symptoms of $\mathrm{CD}$ observed in this study are consistent with the findings of Findling et al. ${ }^{5}$ However, in addition to improvement in symptoms of $\mathrm{CD}$, we found significant improvements in inattention and hyperactivity/ impulsivity, whereas Findling et $\mathrm{al}^{5}$ did not. We originally hypothesized that risperidone treatment might have led to reductions in hyperactivity/impulsivity similar to those found by Turgay et al. ${ }^{8}$ Improvement in hyperactivity also has been reported in autistic children. ${ }^{7}$ However, the significant improvement seen in the inattention ratings of teachers and parents in our study was unexpected. Because a well-known side effect of atypical antipsychotic drugs is sedation, we did not anticipate improvement in inattention. Similarly unexpected improvements, such as improvement on the Psychosomatic T score of Conners Parent Rating Scale in the study by Findling et al, ${ }^{5}$ have been previously reported. The investigators suggested that unexpected improvement resulted from a better overall sense of well-being in those children. The significant improvement in the teacher and parent ratings of inattention found in this study also could be 
explained in a similar fashion, that is, as overall improvements in hyperactivity/ impulsivity, ODD, and CD. Nicolson et $\mathrm{al}^{7}$ reported that autistic children who responded to risperidone treatment were better able to focus on their work at school. This result is also consistent with our findings of the improvement in inattention. However, the beneficial effects of risperidone on inattention must be regarded as a tentative hypothesis until additional controlled studies have shown that risperidone is effective in improving inattention in children and adolescents with CD.

The mean final dosage of risperidone $(1.27 \mathrm{mg} / \mathrm{d})$ was relatively low compared with the dosages typically used in the treatment of schizophrenia but was similar to the dosages used in previous studies of the treatment of children and adolescents with $\mathrm{CD} .^{5,8}$ In another study ${ }^{10}$ conducted with children and adolescents with $\mathrm{ADHD}$, ODD, and $\mathrm{CD}$, the mean final dosage of risperidone $(1.20 \mathrm{mg} / \mathrm{d})$ was almost the same as the final dosage reported in our study. As Findling et $\mathrm{al}^{5}$ stated, low doses of risperidone seem to be effective in treating children and adolescents with CD.

Risperidone was well tolerated in our study, and no patient was discontinued from the study because of adverse events. Similar to the findings of previous studies $^{5,7,8}$ in which risperidone was used in low doses, the only important adverse event in our study was body weight gain. In 2 reviews ${ }^{6,12}$ of pharmacotherapy studies in children and adolescents with pervasive developmental disorders, the investigators suggested that low doses of risperidone may cause body weight gain. The mean (SD) body weight gain of $1.6 \mathrm{~kg}(1.9 \mathrm{~kg})$ in our study is lower than that reported in the previous studies. The lower levels of body weight gain in our study may have been the result of investigators warning parents about this side effect.

No evidence of marked sedation, extrapyramidal symptoms, abnormalities in liver function, or significant changes on electrocardiography or complete blood count was found in our study. As explained by Findling et al, ${ }^{21}$ initiating risperidone treatment at low doses and titrating the drug gradually can significantly reduce the risk for extrapyramidal symptoms. Results of previous short-term studies $^{6,12}$ with low-dose risperidone also suggested that risperidone is well tolerated in children and adolescents, which is consistent with our findings.

\section{Study Limitations}

The results of our study should be interpreted cautiously because of several limitations. Most importantly, this was an open-label trial without a placebocontrol group. Other important limitations of the study were its small sample size and short duration. Further studies, particularly with a double-blind, placebo-controlled design and larger samples, are needed to better define the clinical use of risperidone in children and adolescents with CD.

\section{CONCLUSIONS}

The results of this study are consistent with previous findings and suggest that risperidone may be an effective and well-tolerated atypical antipsychotic drug 
for the treatment of children and adolescents with CD. However, further studies, particularly placebo-controlled and double-blinded, are needed to better define the clinical use of risperidone in children and adolescents with CD.

\section{REFERENCES}

1. American Psychiatric Association. Diagnostic and Statistical Manual of Mental Disorders, Fourth Edition (DSM-IV). Washington, DC: American Psychiatric Association; 1994:103-110.

2. Steiner H. Practice parameters for the assessment and treatment of children and adolescents with conduct disorder. American Academy of Child and Adolescent Psychiatry. J Am Acad Child Adolesc Psychiatry. 1997;36(Suppl 10):122S-139S.

3. Hechtman L, Offord DR. Long-term outcome of disruptive disorders. Child Adolesc Psychiatr Clin N Am. 1994;3:379-404.

4. Gracious BL, Findling RL. Antipsychotic medications for children and adolescents. Pediatr Ann. 2001;30:138-145.

5. Findling RL, McNamara NK, Branicky LA, et al. A double-blind pilot study of risperidone in the treatment of conduct disorder. J Am Acad Child Adolesc Psychiatry. 2000;39:509-516.

6. Posey DJ, McDougle CJ. The pharmacotherapy of target symptoms associated with autistic disorder and other pervasive developmental disorders. Harv Rev Psychiatry. 2000;8:45-63.

7. Nicolson R, Awad G, Sloman L. An open trial of risperidone in young autistic children. J Am Acad Child Adolesc Psychiatry. 1998;37:372-376.

8. Turgay A, Aman M, Binder C, et al. Risperidone in children with oppositional defiant disorder, conduct disorder, subaverage IQ, and comorbid ADHD. Paper presented at the 48th Annual Meeting of the American Academy of Child and Adolescent Psychiatry; October 23-28, 2001; Honolulu, Hawaii.

9. Perry R, Pataki C, Munoz-Silva DM, et al. Risperidone in children and adolescents with pervasive developmental disorder: Pilot trial and follow-up. J Child Adolesc Psychopharmacol. 1997;7:167-179.

10. Simeon J, Milin R, Walker S. A retrospective chart review of risperidone use in treatment-resistant children and adolescents with psychiatric disorders. Prog Neuropsychopharmacol Biol Psychiatry. 2002;26:267-275.

11. Schreier HA. Risperidone for young children with mood disorders and aggressive behavior. J Child Adolesc Psychopharmacol. 1998;8:49-59.

12. McDougle CJ, Scahill L, McCracken JT, et al. Research Units on Pediatric Psychopharmacology (RUPP) Autism Network: Background and rationale for an initial controlled study of risperidone. Child Adolesc Psychiatr Clin N Am. 2000;9:201-224.

13. Achenbach TM, Edelbrock C. Manual for the Child Behavior Checklist/4-18 and revised child behavior profile. Burlington, Vt: University of Vermont, Department of Psychiatry; 1983.

14. Erol N, Kılıç C, Ulusoy M, et al. Mental Health Profile of Turkey [in Turkish]. Ankara, Turkey: TC Sağlık Bakanlığı Temel Sağlık Hizmetleri Genel Nüdürlüğü; 1998.

15. Turgay A. Disruptive Behavior Disorders: Child and Adolescent Screening and Rating Scales for Children, Adolescents, Parents and Teachers. West Bloomfield, MI: Integrative Therapy Institute Publication; 1994.

16. Ercan ES, Amado S, Somer O, Çıkoğlu S. Development of a test battery for the assessment of attention deficit hyperactivity disorder [in Turkish]. Çocuk ve Gençlik Ruh Sağlığı Dergisi. 2001;8:132-144. 
17. National Institute of Mental Health. CGI (Clinic Global Impression) Scale. Psychopharmacology Bull. 1985;21:839-843.

18. Wechsler D. Wechsler Preschool and Primary Scale of Intelligence. Revised edition. New York: Harcourt Brace; 1983.

19. Kovacs M. Rating scale to assess depression in school aged children. Acta Paedopsychiatr. 1981;46:305-315.

20. Chouinard G, Ross-Chouinard A, Annable L, Jones BD. The extrapyramidal symptom rating scale. Can J Neurol Sci. 1980;7:233.

21. Findling RL, Schultz SC, Reed MD, Blumer JL. The antipsychotics: A pediatric perspective. Pediatr Clin North Am. 1998;45:1205-1232.

\section{Address correspondence to:}

Eyüp Sabri Ercan, MD

Ege Üniversitesi

Tıp Fakültesi Psikiyatri AD 35100

Bornova, İzmir

Turkey

E-mail: eyercan@hotmail.com 